\title{
A Holistic Review for Inspiration Economy Framework Constructs
}

\author{
Mohamed Buheji \\ International Institute of Inspiration Economy - Morocco \\ E-mail: buhejim@gmail.com \\ Dunya Ahmed \\ International Institute of Inspiration Economy - Morocco \\ E-mail: dr.dunya@hotmail.com
}

Received: November 12, 2016 Accepted: December 22, 2016 Published: December 27, 2016

doi: $10.5296 /$ jsss.v4i1.10514

URL: http://dx.doi.org/10.5296/jsss.v4i1.10514

\begin{abstract}
As the world is trying to discover what the shape of the much-needed next economy and socio-economy will be, this study attempts to explore the possibility of a framework that would address holistically the different inspiration economy driven constructs that have already been presented by researchers and authors. With the development of humanity and the fast pace of a knowledge-based economy, inspiration is becoming an ever more essential factor for the development of any socio-economy.

The study of the inspiration economy framework by the knowledge community is still in its infancy, especially if the need for deeper work, as explored in the work of Thrash and Elliot (2010, 2004, 2003) and the Handbook of Inspiration Economy by Buheji and Thomas (2016), are acknowledged. A review of the literature shows that the body of knowledge has not so far established a robust theoretical framework that will guide researchers from a holistic perspective and demonstrate how the inspiration economy can be approached by researchers.

This study aims to address a general question: how the inspiration economy can be approached by researchers. In seeking an answer to this question, the paper has two objectives: 1) to review how researchers are seeing the constructs of the inspiration economy framework, taking into account the available literature; 2) to develop recommendations about the research that would contribute towards unleashing the constructs of the coming
\end{abstract}


inspiration economy. Finally, a set of conclusions is presented. This offers a better understanding of the inspiration economy with the aim of improving future research that would, in turn, enhance both discussions on and knowledge of the subject.

Keywords: Inspiration economy, Holistic review, Frameworks

\section{Introduction}

Prior to this, although the work of Thrush and Elliott $(2004,2003)$ offered a deep understanding of inspiration, researchers have considered many areas relevant to inspiration, albeit in a variety of ways. Thus, so far, there has been limited research that has focused on the "what" and "how" of inspiration and its relevance to socio-economics.

On the basis of a literature review, this paper first discusses the definition of inspiration, its background and research foundations of the inspiration economy so far; it then considers types of constructs and their specific implications. The paper ends by recommending several promising areas for future research which focus on suitable constructs for an inspiration economy.

\section{Literature Review}

After the development of many inspiration theories, there are still gaps in the literature that show that inspiration is not yet understood as a make or break concept in life. However, different researches in recent years, such as that of Buheji et al. (2014) and previously those of Thrush and Eliott (2003 and 2004), have focused on the importance of inspiration approaches to enhance the value of self-realisation, self-worth, self-value and self-independence.

\subsection{Definition of a Construct}

The Cambridge Dictionary defines a construct as something that helps to build or put something together, or the making of different parts that will form a whole.

In a research context, the term construct refers to the characteristic or trait that is being evaluated. Some examples of constructs are indirect, such as measuring intelligence levels or levels of satisfaction, for example. Other types of construct measure reactions to certain instances. This research explores all these types of construct to ensure they help in building a framework for the coming inspiration economy (Lavrakas, 2008).

\subsection{Importance of Understanding the Constructs of Inspiration}

Inspiration was conceptualized in terms of both its purpose or function by Thrash and Elliot (2004), and later by Thrash et al. (2010b). It has been found to motivate the transmission of newly appreciated qualities of a particular object and is a good mediator among different variables. A creative idea may inspire an individual to bring the idea into fruition in the form of a creative invention or a tangible product and/or service. Thus, inspiration was considered, by Thrash's team at least, to be a motivational response to many creative ideas.

With inspiration, the transmission that happens with certain levels of ability to transform a society or come up with innovations can be explained. However, many more studies need to 
be developed to explore how inspiration approaches can effect transformations from being situational, to becoming self-driving forces and thence to cognitive and non-cognitive powers (Buheji \& Thomas, 2016; Simonton, 2003; Baas et al., 2013).

Devoldere et al. (2014) mentioned life-long learning as an important construct for an inspiration economy. Inspiration as seen by Devoldere et al. focused on the adoption of ideas generated from the crossovers created between different contexts.

\subsection{Importance of an Holistic Approach to Inspiration}

Life cannot develop with only specializations and sub-specializations as it needs both specialization and non-specialization tracks but also hybrid paradox tracks that allow us to see the big picture. Only with a specialization track can important and complex life problems be solved and only with a hybrid track can we achieve detailed, planned and developed inspiration. Therefore, both are needed (Buheji et al., 2014).

Today, however, life is developing fast and special track education in most countries has lost its holistic thinking which is a main source for inspiration. Yet, due to its power, holistic thinking can uncover blind spots around us. In fact, such holistic thinking used to be a source of excitement for many scientists between the time of Ibn Sinatill and Einstein.

The recent work of researchers in inspiration, such as Thrash and Elliot (2003) and, before that, Solomon (1983), has shown that people with proactive stimuli often outperform those who are under-inspired in terms of both quantity and quality.

\subsection{Inspiration Economy Research so far}

The inspiration economy is about creating a life system and a way of being, not just doing. In fact, the inspiration legacy focuses on practices where one part is about "being", and two parts concern "doing". So, one could confirm that the inspiration economy research is still in its infancy compared to practical development.

Inspiration-driven constructs that are related to socio-economic issues and applied research are increasing more and more every day. Those societies who have used the real benefits of a knowledge economy, like advanced European societies, began to see the rationale for being a source of inspiration rather than just being focused on efficiency (Feurstein \& Schumacher, 2008). Thus, the current scarcity of deep research into the area of inspiration has created a clear gap for research that would allow the constructs of such an inspiration economy framework to be explored in different societies.

\section{Methodology}

The researchers collected observations on the constructs of inspiration and its effect on the socio-economy from all papers presented in Inspiration Economy Forums during the year 2015/2016.

Approaches regarding inspiration were considered from papers presented in five consequent forums on the Inspiration Economy in the years 2015 and 2016 in different countries around the world. The papers were investigated after their themes were carefully examined. The papers were mainly differentiated into four categories using the directions of Ketcham and Crawford (2007). 
The methodology focused on categorising the papers based on the constructs of the inspiration economy; they were not based on the "what is" and "how" themes. This methodological choice was justified by the study's aims and reinforced by other studies applied in investigating approaches to a phenomenon (Elliot \& Thrash, 2010).

\subsection{Category 1 Research: Constructs Focusing on Aspiration and Their Effect on an Inspiration-based Economy}

Papers here tried to define boundaries of inspiration. Some researchers found that much aspiration failed because it never achieved the critical mass and thus failed from its first steps. People differed in their aspirations because they could see the bigger picture and would thus strive to find even more challenging opportunities to achieve that visualisation. This suppored the work of Thrash and Elliot (2003).

To illustrate the type of papers which fell under this category: some papers focused on the type of challenges that faced those striving towards inspiration, including entrepreneurs. Some papers tried to address what blocked inspiration and what triggered it while certain papers tried to investigate how aspiring ideas managed to inspire and influence societies.

What is interesting is that in all the forums different papers focused on the empowerment of youth in creating more positive observations that excited the mindsets of people, where the mindsets involved the mind's predisposition to certain ideas, values, people and systems. Other papers asserted that the main differentiation in inspiration came from loyalty and willingness; this enhanced organisational memory by $80 \%$ in comparison to a rewards system which guaranteed only $20 \%$.

It is worth noting that the aspiration construct elicited by the impact and development of technology showed only a limited importance for inspiration, according to the 70 papers presented in these specialized forums. Some authors saw role of passivity (i.e. not expressing one's real point of view to avoid consequences or contradictions, or avoiding being alienated or misinterpreted) controlled people's inspiration. Avoiding trying or speaking up, as shown by different authors, meant that people avoided inspiration. Other authors discussed how to move from production or development, where people would follow their aspirations, to personhood where people would follow their actual personality: i.e. who they are.

\subsection{Category 2 Research: Constructs Focusing on How Inspiration Strengthen Insights and Proactive Thinking}

Inspiration during difficult times or how to overcome difficult times was discussed by many researchers in the $3 \mathrm{rd}, 4$ th and 5 th forums as part of the main theme. However, most the research presentations and papers were found to be in the area of how inspiration helps in setting the mindsets that would overcome certain behaviour, emotions, thoughts and environmental challenges.

Most of the papers discussed persistence as a construct to inspiration, which was thus a very important variable in inspiration currency. Other papers focused on the type of inspiration that would strengthen people's insights. Recent papers also discussed the competitiveness of individuals and societies due to the role of inspiration in lifelong learning and in creating positive change, including the role of inspiration in human development. 


\subsection{Category 3 Research: Constructs Focusing on the Sources of Inspiration}

Many researchers mentioned the traditional sources of inspiration. However, certain research papers showed that such sources of inspiration are not fixed and cannot be easily determined. Inspiration can be triggered as certain researchers come from traditional known frameworks or understood norms. According to certain researchers, these construct sources usually differ in the strength of their impact and influence. Some sources of inspiration open new perspectives and thus create a real change in mindsets. For example, an Egyptian professor of Zuwail Technological City asserted that inspiration waves can be created through university methods of teaching in a turbulent society. Others focused on the sources of well-being and immunity as a source of inspiration in building organisational spirit. This supports the work of Thrash and Elliot (2004) regarding the core characteristics of inspiration, and Thrash et al. (2010) on the role of inspiration and the promotion of well-being.

Certain papers focused on the external sources of inspiration, such as family, environment, community, education, etc.. Others said that inspiration came from within (e.g. processes and practices that change mindsets); this would be a source for creating learning and raising the capacities of individuals and society.

Learning by doing: i.e. learning from failures, holistic thinking, reflections, interactions, or even learning from formal educational settings, were also found to be favourable constructs in terms of creating inspiration-based socio-economies.

\subsection{Category 4 Research: Constructs Focusing on how Inspiration Influences Societies}

Researchers here tried to look at different constructs from new perspectives that would have an influence on societies and thus economies. Certain researchers considered how the power of visualisation increased curiosity and focus; these helped create more inspiration which gave rise to better ideas. Other authors viewed inspiration as a pain and discussed how pain enhances the creation of ideas; this is an important construct for a better socio-economy. Other constructs focused on learning from healthy feelings which were thought to trigger further inspiration. Under this area of research, constructs such as challenges and changes were highly linked to inspiration.

\subsection{Category 5 Research: Construct of Ideas as part of a Better Economy}

Here the researchers discussed mainly how idea creation as a construct created the stimuli for inspiration. Idea creation was seen as a means of making progress that came from action. Internally examining and exploring an issue of concern, which was triggered by an experience, created and clarified meaning in terms of self; this resulted in a changed conceptual perspective. Idea creation, as a construct in relation to fostering creativity, innovation and inspiration, was also presented by certain researchers.

The role of meditation in the inspiration approach was discussed in detail as it is a main source of the construct of idea creation. Other papers covered the role of the humanities and arts in creating the process. Other types of paper focused on the construct of young people's idea creation. 


\subsection{Category 6 Research: Construct of the Role of Inspiration in Success}

Inspiration, as confirmed by certain researchers, was found to lead to game changing, thus offering a fresh source of ideas coming from different channels.

Researchers here focused on the importance of studying how inspiration changes a game from competitiveness to differentiation, profits and the ability to create inspiration.

\section{Synthesis of the Constructs of the Six Types of Research}

Most of the research papers were easily segregated and categorised into the following types of construct: aspiration and the journey of inspiration, inspiration insights and inspiration sources, inspiration influences, the process of idea creation, inspiration and the creation of success stories. However, many papers were imbued with a sense of confusion compared to the handbook of Buheji and Thomas (2016).

One of the most common sources of confusion observed in outlining the constructs was the confusion between inspiring and inspirational. Researchers were found to use more often the word 'inspirational' which usually indicates an intent-based state, while the word 'inspiring' was meant to reflect the effect of inspiration. In order to reflect the main keywords that created the constructs of the 60 papers reviewed, the researchers devised Table 1 to compare the repeated keywords in each of the categories defined in the research studies.

Table 1. Main and secondary keywords of constructs

\begin{tabular}{|c|c|c|}
\hline Paper Category Type & Main Keywords & Secondary Keywords \\
\hline $\begin{array}{l}\text { Category 1: what type of } \\
\text { aspirations people have and } \\
\text { why they differ in the } \\
\text { journey of inspiration. }\end{array}$ & $\begin{array}{lr}\text { Challenges } & \text { facing } \\
\text { inspiration } & \text { and } \\
\text { entrepreneurship. } & \end{array}$ & $\begin{array}{l}\text { What triggers inspiration; } \\
\text { investigation of how aspiring ideas } \\
\text { are managed; how inspiration } \\
\text { influences societies. }\end{array}$ \\
\hline $\begin{array}{l}\text { Category } 2: \quad \text { How } \\
\text { inspiration strengthens our } \\
\text { insights and thus speeds up } \\
\text { our proactive thinking. }\end{array}$ & $\begin{array}{l}\text { Inspiration in difficult } \\
\text { times or in how to } \\
\text { overcome } \\
\text { times. }\end{array}$ & $\begin{array}{l}\text { Inspiration that would strengthen } \\
\text { our insights. }\end{array}$ \\
\hline $\begin{array}{l}\text { Category 3: What are the } \\
\text { sources of inspiration? }\end{array}$ & $\begin{array}{l}\text { Sources of inspiration } \\
\text { are not fixed and can't } \\
\text { be easily determined. }\end{array}$ & $\begin{array}{l}\text { Learning by doing: i.e. learning } \\
\text { from failures, holistic thinking, } \\
\text { reflections, interactions, or even } \\
\text { learning from formal educational } \\
\text { settings and diversity management. }\end{array}$ \\
\hline Paper Category Type & Main Keywords & Secondary Keywords \\
\hline $\begin{array}{l}\text { Category } 4: \quad \text { How } \\
\text { inspiration helps ideas } \\
\text { which have an influence on } \\
\text { societies and the world. }\end{array}$ & $\begin{array}{l}\text { Visualisation, } \\
\text { inspiration, pain, idea } \\
\text { creation. Inspiration and } \\
\text { learning }\end{array}$ & Curiosity and focus; idea creation. \\
\hline Category 5: papers on idea & creation & perspectives \\
\hline
\end{tabular}




\begin{tabular}{|l|l|l|}
\hline creation & $\begin{array}{l}\text { creates the stimuli of } \\
\text { inspiration. }\end{array}$ & $\begin{array}{l}\text { inspiration, idea creation and } \\
\text { creativity, innovation and } \\
\text { inspiration. }\end{array}$ \\
\hline $\begin{array}{l}\text { Category 6: papers on } \\
\text { whether inspiration leads to } \\
\text { success. }\end{array}$ & Game changing. & Inspiration sources. \\
\hline
\end{tabular}

\section{Discussion}

This paper was divided into two parts, according to the objectives of the study. The first objective was to discuss what inspiration is according to specialised researchers. Each research study in the six categories presented a non- addressed construct of inspiration. This is very important in setting up future research for the inspiration economy and its influence on the socio-economy. The second objective was to apply and open up these constructs in terms of their relevance to the framework of the inspiration economy. Moreover, it suggests gaps in the body of knowledge in relevance to inspiration-based economic constructs.

The first, and part of the second objective, were achieved through the organization and presentation of papers, linking these to the literature published in recent years. These were compared to the available theoretical approaches applied to the constructs of the inspiration economy.

In line with the rest of the second objective of this study, a holistic approach to the inspiration economy was discussed. This integrated the different constructs and then a framework was suggested. Figure 1 shows the suggested framework based on a synthesis of the reviewed literature and the outcome of the inspiration-focused papers that were analysed. The framework shows that aspiration leads to a journey in the inspiration economy; it also becomes a source of inspiration which moves the inspiration to shift normal insights, making it a real source of strength in future socio-economies. Sources of inspiration create and influence other ideas, similar to insights or strengths, thus enhancing the ability to create ideas. These lead to success stories or even speed up proactive thinking.

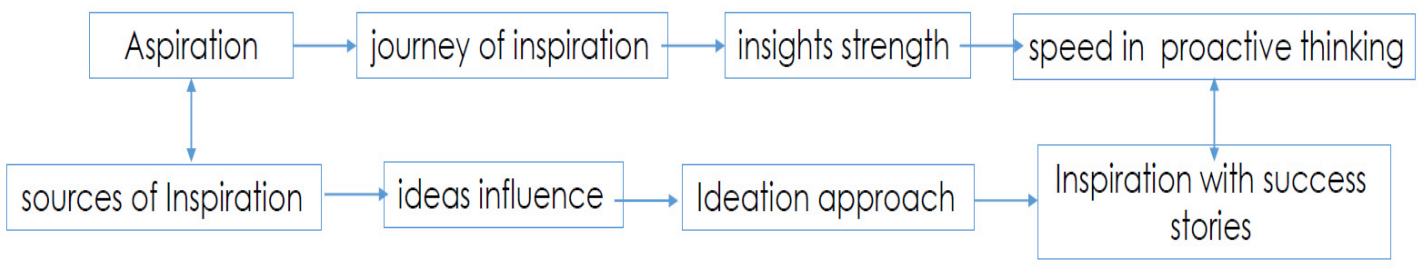

Figure 1. Framework of inspiration economy constructs

\section{Conclusion}

Six categories of papers concerning inspiration were the subject of study after being 


\section{Macrothink Institute ${ }^{\text {TM }}$}

identified and analysed, following special forums that focused on the subject of the inspiration economy during the year $2015 / 2016$. The literature review suggested that there is a need for in-depth and also diverse studies in this area in the future.

The framework suggests, as per the outcome of the synthesis of all the papers presented, that these are the main keywords so far and through them, a new way of looking at inspiration economy constructs and their role in creating a proactive society and success stories can be achieved.

Further research is now necessary in this area since constructs of the future inspiration economy have never been properly explored.

\section{References}

Buheji, M., \& Thomas, B. (2016). Handbook of Inspiration Economy. Natural Science Publishing, USA.

Buheji, M. (2016). Inspiring Government, Natural Science Publishing, USA.

Buheji. M., Saif, Z., \& Jahrami, H. (2014). Why Inspiration Matters? Journal of Inspiration Economy, 1(1), UOB Publication Centre.

Devoldere, B., Beulens, M., Debruyne, M., De Stobbeleir, K., Meuleman, M., \& Sleuwaegen, L. (2014). De inspiratie economie: Een toekomstvisie voor de regionale ontwikkeling van Vlaanderen. Vlerick Business School \& Flanders DC.

Elliot, A., \& Thrash, T. (2010) Approach and avoidance temperament as basic dimensions Journal of personality, 78(3), 865-906. https://doi.org/10.1111/j.1467-6494.2010.00636.x

Ketcham, C. M., \& Crawford, J. M. (2007). The impact of review articles. Lab Invest, 87, 1174-1185. https://doi.org/10.1038/labinvest.3700688

Lavrakas, P. (2008). Encyclopedia of Survey Research Methods, Se Publications. https://doi.org/10.4135/9781412963947

Ming, Y., \& Jin, Y. (2011). Bio-Inspired Self Organising Robotics Systems, Studies in Computational intelligence, 355.

Thrash, T. M., \& Elliot, A. J. (2003). Inspiration as a psychological construct. Journal of Personality and Social Psychology, 84, 871. https://doi.org/10.1037/0022-3514.84.4.871

Thrash, T. M., \& Elliot, A. J. (2004). Inspiration: core characteristics, component processes, antecedents, and function. Journal of personality and social psychology, 87, 957-973. https://doi.org/10.1037/0022-3514.87.6.957

Thrash, T. M., Elliot, A. J., Maruskin, L. A., \& Cassidy, S. E. (2010) Inspiration and the promotion of well-being: Tests of causality and mediation. Journal of Personality and Social Psychology, 98, 488-506. https://doi.org/10.1037/a0017906

Thrash, T. M., Maruskin, L. A., Cassidy, S. E., Fryer, J. W., \& Ryan, R. M. (2010). Mediating between the muse and the masses: inspiration and the actualization of creative ideas. Journal of personality and social psychology, 98, 469-487. https://doi.org/10.1037/a0017907

Thrash, T., Elliot, A., Maruskin, L., \& Cassidy, S. (2010). Inspiration and the promotion of well-being: Tests of causality and mediation. Journal of Personality and Social Psychology, 98(3), 488-506. https://doi.org/10.1037/a0017906 


\section{Macrothink}

Journal of Social Science Studies

ISSN 2329-9150

\section{Copyright Disclaimer}

Copyright for this article is retained by the author(s), with first publication rights granted to the journal.

This is an open-access article distributed under the terms and conditions of the Creative Commons Attribution license (http://creativecommons.org/licenses/by/3.0/). 